\title{
EDITORIAL
}

This is the first issue of volume 5 of the Australian Journal of Information Systems. As Editor, I am pleased to report the on-going interest in the journal, both from authors and more recently from a number of intemational conferences who have kindly agreed to advertise the journal to their participants.

Our first paper - A Comparison of Five Alternative Approaches to Information Systems Development - Rudy Hirschheim, University of Houston, Juhani Iivari, University of Oulu and Heinz Klein, SUNY University Binghampton - compares and contrast the major Developmental Approaches in the light of emerging technologies. The authors provide both background as well as future trends in the approaches.

Our second paper - Assessing Software Cost Estimation Models: Criteria for Accuracy, Consistency and Regression - Bruce Lo and Xiangzhu Gao - provides two new models: the weighted mean of quartiles and the standard deviation of the ratios of estimates. The results suggest that these new measures may overcome some of the hitherto found difficulties.

Our third paper is entitled - A Pilot Study of Small Business's Perception of Vendor Provided Services: Are These Associated with Small Business IT Educational Requirements? - Rob MacGregor \& Deborah Bunker, University of Wollongong, Joan Pierson and Karen Forcht, James Madison University. This paper examines the type of IT training required by small business managers and questions whether the type of required training is associated with satisfaction with vendor services.

Graham Pervan, Curtin University of Technology provides our next paper entitled - Information Systems Management: An Australasian View of Key Issues - 1996. This paper is part of a longitudinal study. The key issues revealed include the need for a technology/business and People skill mix in IS executives.

Our next paper - The Role of Conferences and Refereed Journals In Australian Information Systems Research - by Gail Ridley, University of Tasmania reports on a survey conducted across Australian academics as to their perceptions concerning conferences and journals. The paper also compares its results with North American data.

Our final paper is entitled - Executive Support of Information Technology and Information Systems in Australian Hospitals: An Empirical Study - by Graeme Rose, Charles Sturt University and Robert Reeve, Macquarie University. This paper examined the concepts of executive participation and executive involvement and their relationship on progressive use of IT in Australian Hospitals. The results showed that there was a strong relationship between executive involvement and progressive use of $\Pi$.

Once again I would like to pass on my thanks to the authors and consulting editors for the high quality of material in this issue. I would also like to thank David Dodds for his assistance in producing final copy of the journal and the maintenance of the Home page.

\section{R. MacGregor}

Editor 